\title{
Signo de Frank en la Roma imperial
}

\author{
Pedro Gargantilla-Madera, Noelia Arroyo-Pardo, Emilio Pintor-Holguín
}

Queremos felicitar a Baños y Guardiola por su excelente artículo titulado 'Utilidad de los textos literarios en la docencia de ciencias de la salud: ejemplos en cardiología, recientemente publicado en la revista. Nos llamó especialmente la atención el análisis que realizan de la novela de ficción Mèmoires d'Hadrien, de Marguerite Yourcenar, y queríamos aprovechar la ocasión para realizar algunos comentarios.

La medicina, con independencia de los avances tecnológicos y terapéuticos en los que se sustenta, es una ciencia eminentemente clínica. Por este motivo es muy importante realizar una correcta anamnesis, como la que se puede deducir del libro de la escritora francesa, y una exploración física minuciosa, en la que se buscan determinados signos clínicos que apoyen la sospecha diagnóstica inicial. En la novela se recoge, por ejemplo, la existencia de edemas en miembros inferiores y de ortopnea que sufrió el emperador. Si observamos con atención las esculturas conservadas del emperador Adriano, como las que se encuentran en el Metropolitan Museum de Nueva York, en el Museo del Prado y en el Museo Arqueológico de Atenas, apreciaremos la existencia del signo de Frank [1], hecho que apoya la presunción diagnóstica.
En 1973, Frank describió la asociación entre la hendidura diagonal del lóbulo de la oreja y la cardiopatía isquémica [1]. El signo del lóbulo hendido ('signo de Frank') se caracteriza por una hendidura diagonal del lóbulo del pabellón auricular que parte del polo inferior del conducto auditivo externo y corre diagonalmente hacia atrás dirigiéndose, en un ángulo de $45^{\circ}$, al borde del lóbulo.

Así pues, la existencia del signo de Frank en algunos bustos del emperador romano [2] apoya la hipótesis de la etiología isquémica como origen de la insuficiencia cardiaca. En nuestra opinión, debemos estimular a los estudiantes de medicina en la búsqueda de signos físicos en las obras de arte que puedan conducir a una presunción diagnóstica, lo cual reitera la estrecha relación existente entre las humanidades y la profesión médica.

\section{Bibliografía}

1. Frank ST. Aural sign of coronary-artery disease. N Engl J Med 1973; 289: 327-8.

2. Petratkis NL. Diagonal earlobe creases type A behavior and the death of Emperor Hadrian. West J Med 1980; 132: 87-91.
Servicio de Medicina Interna; Hospital El Escorial (P. Gargantilla-Madera, N. Arroyo-Pardo). Universidad Europea de Madrid (P. GargantillaMadera, E. Pintor-Holguín). Madrid, España.

Correspondencia:

Dr. Pedro Gargantilla Madera. Servicio de Medicina Interna. Hospital El Escorial. Ctra. M-600 de Guadarrama a San Lorenzo de El Escorial, km 6,255. E-28200 San Lorenzo de El Escorial (Madrid).

E-mail: pgargantilla@yahoo.es (c) 2015 FEM 